\title{
O RELACIONAMENTO DAS COMPETÊNCIAS LEITORA E EM INFORMAÇÃO COM O PROCESSO DE LETRAMENTO NA ERA DIGITAL
}

\section{THE RELATIONSHIP OF READING AND INFORMATION COMPETENCE WITH THE LITERACY PROCESS IN THE DIGITAL AGE}

Meri Nadia Marques Gerlina

\begin{abstract}
RESUMO
Introdução:.As tecnologias de escrita, informação e comunicação potencializam a disseminação da informação, possibilitando a recuperação de obras impressas, eletrônicas e digitais em vários tipos de suportes como livros, periódicos, vídeos e web sites. Por meio do uso dos recursos tecnológicos enormes volumes de informações são disponibilizados, tornando-se necessário que o sujeito contemporâneo desenvolva competências no âmbito da informação e da leitura destinadas à promoção de aprendizagens significativas, em decorrência do uso de diferentes modalidades de textos e hipertextos perpassando o interesse, a necessidade e o prazer de ler. Objetivo: O cenário apresentado requer colocar em análise o desenvolvimento da competência leitora e da competência em informação relacionadas com o processo de letramento na era digital. Metodologia: Por meio de uma pesquisa descritiva e exploratória caracterizada a princípio como bibliográfica, identificam-se temas e procede-se ao delineamento de direcionamentos para as competências desenvolvidas na biblioteca, na escola, no ciberespaço, na universidade e em outros ambientes colaborativos de (in)formação, educação e cultura. Resultados: No decorrer da análise dos temas e direcionamentos que compreendem as competências leitora e em informação interrelacionadas com o processo de letramento, verifica-se que o acesso das modalidades de leituras multimodais e a capacidade de compreensão são essenciais para a apropriação do (hiper)texto. Identifica-se que o exercício de uma leitura crítica, adquirida por meio de um aprendizado colaborativo, requer processos de construção de práticas e projetos de leituras relacionadas com o uso ético da informação, dependendo, por conseguinte, de uma combinação de conhecimentos e atitudes sociais na era digital. Conclusões: Durante o desenvolvimento da pesquisa percebe-se que a sociedade da informação e do conhecimento solicita do sujeito leitor competências que depreendam da combinação de habilidades (saber fazer), conhecimentos (saber ser) e atitudes (saber agir) no campo da informação e da leitura, assim como da aquisição de habilidades cognitivas e atitudes relacionadas com a escrita no âmbito da alfabetização, junto com a mobilização de práticas de leituras socialmente constituídas pelo processo de letramento.
\end{abstract}

\footnotetext{
a Doutora em Ciência da Informação pela Universidade de Brasília (UnB). Docente do Programa de Pós-Graduação em Ciência da Informação da Universidade Federal do Espirito Santo (PPGCINF-UFES). E-mail: merinadia@hotmail.com
} 
Descritores: Competência em informação. Competência leitora. Letramento na era digital. Sociedade da Informação e do conhecimento.

\section{INTRODUÇÃO}

A presença acentuada das novas tecnologias fortalecem processos de busca, recuperação, seleção e uso da informação, tornando acessíveis obras impressas, eletrônicas e digitais disponibilizadas em suportes como livros, periódicos (revistas e jornais), vídeos e web sites. Também facilitam o acesso aos enormes volumes de informações por meio da utilização dos recursos tecnológicos, tornando necessário que o sujeito contemporâneo desenvolva competências para usar equipamentos eletrônicos tanto quanto para se conectar em redes digitais e sociais. Torna-se necessário, portanto, o desenvolvimento das competências no âmbito da informação e da leitura que compreendam conhecimentos, habilidades, técnicas e atitudes destinadas à promoção de aprendizagens significativas diante da apropriação de diferentes textos e hipertextos perpassando o interesse, a necessidade e o prazer de ler diversas modalidades de leituras (CUEVAS, 2008; GERLIN, 2017).

O desencadeamento da competência leitora e da competência em informação encontra-se inter-relacionado com o processo de letramento e com a prática da alfabetização na era digital (SOARES, 2002), tornando-se imprescindíveis para o protagonismo social e para a autonomia do leitor que se encontra conectado por meio de redes presenciais, virtuais e/ou híbridas (CASTELLS, 2011). Esse sujeito, portanto, depende cada vez mais de processos de organização da informação em ambientes colaborativos tanto quanto necessita de ações disseminativas para que possa acessar uma variedade de textos multimodais e alcançar as metas propostas pelo contexto de mudança que a sociedade da informação e do conhecimento apresenta.

Diante do cenário apresentado, desenvolve-se uma pesquisa com o objetivo geral de colocar em análise o desenvolvimento das competências leitora e em informação relacionadas com o processo de letramento na era digital e, especificamente, perceber a importância da identificação de temas e do desenvolvimento de direcionamentos para as competências na biblioteca, na 
escola, no ciberespaço, na universidade e em outros espaços, formais e informais, de educação, informação e cultura.

Para tanto, desenvolve-se uma pesquisa descritiva e exploratória caracterizada a princípio como bibliográfica e realizada no âmbito da Ciência da Informação e áreas afins como a Educação e a Tecnologia de Informação, colocando em questão temas e o delineamento de direcionamentos ao partir da produção de autores e pesquisadores, nacionais e internacionais, como: Araújo Júnior (2007); Bedin, Chagas e Sena (2015); Belluzzo e Feres (2015); Castells (2003, 2011); Cavalcante e Rasteli (2013); Cuevas (2008); Gerlin (2017); Gomes e Santos (2019); Gulka e Lucas (2018); Lévy $(2010,2011)$; Soares $(2002,2004)$ e Varela, Barbosa e Farias (2017); dentre outros.

\section{LETRAMENTO, COMPETÊNCIA, LEITURA E INFORMAÇÃO EM QUESTÃO}

$\mathrm{Na}$ denominada era digital as ferramentas tecnológicas proporcionam a leitura de conteúdos em suportes tradicionais como livros, periódicos e jornais por meio da utilização de equipamentos como computadores, leitores de livros eletrônicos, tabletes e smartphones. Na referida época, também denominada como era da informação, intensificam-se processos de disponibilização das tecnologias de informação e comunicação em um movimento de conexão da sociedade em rede fortalecido no final do século XX. Essa nova estrutura de leitura requerida pela sociedade da informação, caracterizada pela ampla utilização das tecnologias de comunicação e pela inovação organizacional, oferece novas formas de atuação social e profissional decorrentes da potência da conectividade das redes de colaboração centradas no usuário de informação (CASTELLS, 2011).

A expressão 'sociedade da informação' deve ser entendida como abreviação (discutível!) de um aspecto da sociedade: o da presença cada vez mais acentuada das novas tecnologias de informação e comunicação [...] Não serve para caracterizar a sociedade em seus aspectos relacionais mais fundamentais (ASSMAN, 2000).

A sociedade da informação baseia-se na presença acentuada das 
tecnologias de informação e comunicação, enquanto que a sociedade da aprendizagem e/ou do conhecimento centra-se no oferecimento de estratégias educativas que proporcionam aprendizagem continuada e transformação social (ASSMANN, 2000). "A mudança terminológica de sociedade da informação para sociedade do conhecimento sinaliza que o conteúdo, e não a tecnologia da informação, é o principal desafio tanto para a economia quanto para a sociedade em geral" (CAPURRO; HJORLAND, 2007, p. 174). Essas denominações se complementam em um cenário que exige do usuário de informação a combinação de habilidades (saber fazer), conhecimentos (saber ser) e atitudes (saber agir) direcionadas para o desenvolvimento de aprendizagens e para a superação da desigualdade social que coexiste com a disponibilização das novas tecnologias (BELLUZZO, 2007).

Decorre que a potencialização dos processos de apropriação e compartilhamento da informação podem dirimir a desigualdade que permeia as práticas dos sujeitos inseridos na sociedade da informação e do conhecimento. Todavia, não se pode desconsiderar que a ausência de infraestrutura tecnológica e de habilidades de leituras dificultam a formação de leitores críticos e capazes de acessar, compreender e usar a informação largamente disponibilizada numa era fortalecida pela inovação que a internet e a web proporcionam.

Com a internet surge uma nova concepção de leitura. Primeiramente, pensou-se que a rede diminuiria a necessidade de leitura. Isso, no entanto, não está ocorrendo, porque qualquer pesquisa séria exige muita leitura; mesmo na web necessita-se fazer uma seleção do que é ou não importante. Assim, acaba-se lendo muito mais, em menos tempo, do que se leria em uma biblioteca. A leitura na rede também é muito mais interessante para as novas gerações que já não querem e não dispõem de mais tempo para longos textos lineares (VARELA; BARBOSA; FARIAS, 2017, p. 283).

A nova estrutura de leitura apresentada aos sujeitos de diversas faixas etárias, gêneros, etnias, classes sociais, níveis acadêmicos e escolares requer a criação de políticas inclusivas e ações de formação das competências para minimizar as contradições que atravessam a organização desigual e complexa do conhecimento (VARELA; BARBOSA; FARIAS, 2017). O acesso à informação 
torna-se condição para que a participação do sujeito leitor em redes colaborativas efetivamente aconteça, já que a cultura digital deve proporcionar o compartilhamento de experiências e aprendizagens necessárias ao longo da vida comunitária, profissional, escolar, acadêmica, etc.

$O$ ato de aprender aprendendo e experimentando remete ao diálogo sobre os saberes e fazeres que advêm das competências no âmbito da leitura e da informação, conduzindo aos contextos teóricos e práticos vivenciados em bibliotecas, escolas, comunidades, universidades e ciberespaço (também conhecido como espaço virtual). Esse novo espaço facilita a conexão profissional, cultural e social, oferecendo ambientes diversificados de aprendizagens fortalecidos pelas ferramentas de conexões e de comunicações colaborativas (LÉVY, 2010). Devido ao movimento de colaboração e ações afirmativas de diferentes grupos sociais conectados em redes digitais, "O ciberespaço tornou-se uma ágora eletrônica global em que a diversidade da divergência humana explode numa cacofonia de sotaques" (CASTELLS, 2003, p. 114-115).

A competência leitora é composta por habilidades, conhecimentos e atitudes destinadas à promoção de aprendizagens por meio do uso de diferentes linguagens e modalidades de leituras (CUEVAS, 2008), sendo alimentada por práticas relacionadas com a aquisição da informação e produção de conhecimentos em espaços tempos presenciais e virtuais. A expressão espaço tempo é utilizada para representar diferentes estruturas de interações em ambientes de informação, educação e cultura, considerando as diversas dimensões da vida social ressignificadas pelo uso das novas tecnologias na sociedade da informação e do conhecimento.

Esse tipo de competência no âmbito da leitura solicita a aquisição de técnicas e estratégias de leituras que possibilitam aprendizagens significativas, que compreende a aquisição de uma nova informação que se relaciona com o conhecimento prévio e auxilia no processo de produção de novos conhecimentos, perpassando, com isso, a necessidade, o interesse, o prazer de ler e requerendo um relacionamento com a competência no âmbito da informação que viabiliza o acesso e o uso de textos e contextos informativos, 
literários, de lazer, dentre outras modalidades (GERLIN, 2017). O texto é tradicionalmente denominado como um recurso de leitura e escrita constituído por palavras, frases, parágrafos e sentidos. Diante da variedade de suportes contendo diferentes modalidades de leituras, também pode se referir aos textos que articulam a linguagem escrita, oralizada, sonora, imagética e outras (GERLIN, 2018).

A competência em informação compreende ações específicas e necessárias para viabilizar estratégias de busca e recuperação da informação, bem como o acesso e avaliação de diversas modalidades de conteúdos textuais em espaços tempos de informação, educação e cultura hibridizados (presenciais e virtuais), podendo ser definida como um conjunto de conhecimentos e atitudes necessárias para a obtenção do sucesso de demandas individuais e, principalmente, constituídas por uma combinação de habilidades cognitivas e sociais (BELLUZZO, 2007).

A competência em informação, enquanto competência funcional, na sociedade contemporânea torna-se, pois, crucial para a realização de cada cidadão e para sua plena integração social. O seu desenvolvimento capacita os indivíduos para o acesso, a seleção, a gestão e a avaliação da informação necessária à vida profissional, social e pessoal (BELLUZZO; FERES, 2015, p. 8).

As competências leitora e em informação se complementam ao proporcionar o alcance da informação textual e a produção de conhecimentos que podem ser compartilhados por meio de motivações, atitudes e emoções, bem como pelo intermédio da interação social do leitor com seus pares e outros sujeitos conectados em redes na sociedade contemporânea. Essas competências acabam requerendo um conjunto de habilidades cognitivas e sociais que garantam o sucesso de demandas individuais e coletivas no campo da leitura e escrita, desenvolvendo-se, portanto, no âmbito da alfabetização e do processo de letramento.

A alfabetização é entendida como a aquisição da técnica de um sistema convencional de leitura e escrita. "Assim, por um lado, é necessário reconhecer que alfabetização - entendida como a aquisição do sistema convencional da escrita - distingue-se de letramento - entendido como o desenvolvimento de comportamentos e habilidades de uso competente da leitura" (SOARES, 2004, 
p. 97). Ao ultrapassar o domínio do sistema alfabético e ortográfico, nível de aprendizagem da língua escrita e falada, o letramento transcende a aquisição do código da escrita, leitura e oralidade na medida em que os sujeitos interagem por meio de práticas sociais em espaços tempos de educação formais e informais.

O letramento, por sua vez, focaliza os aspectos sócio-históricos da aquisição da escrita. Entre outros casos, procura estudar e descrever o que ocorre nas sociedades quando adotam um sistema de escritura de maneira restrita ou generalizada; procura ainda saber quais práticas psicossociais substituem nas práticas letradas (TFOUNI, 2010, p. 12).

O processo de letramento engloba comportamentos e práticas sociais letradas contribuindo para que a alfabetização, comumente entendida como um sistema convencional, desenvolva-se por meio da aprendizagem dos sistemas de escrita e de leitura relacionados com o contexto da sociedade atual. $O$ letramento é constituído por meio de práticas articuladas com o meio social e através dos eventos em que elas são experimentadas, exercendo uma influência sobre a sociedade ao organizar e oferecer estratégias para que o estado de "letramento" efetivamente aconteça.

Considerando que letramento designa o estado ou condição em que vivem e interagem indivíduos ou grupos sociais letrados, pode-se supor que as tecnologias de escrita, instrumentos das práticas sociais de leitura e de escrita, desempenham um papel de organização e reorganização desse estado ou condição (SOARES, 2002, p. 148).

A prática da leitura potencializada pelo letramento solicita 0 desenvolvimento de competências que conduzam aos estoques de informações que oferecem condição para que o grupos sociais sejam letrados. A recuperação da informação e a produção de conhecimento são processos interligados que concedem, a priore, uma formação integral e, a posteriore, uma transformação social por meio da aquisição de atitudes e habilidades constituídas em torno do ato de ler de uma maneira diferenciada na era digital. Nessa direção, os textos e contextos disponibilizados nas telas dos equipamentos eletrônicos direcionam o leitor ao ciberespaço - ambiente que oferece um conjunto infinito de informações hipertextuais. O hipertexto é entendido como uma coleção de dados e informações multimodais (texto, som e imagem) disponibilizadas em redes de 
colaboração (LÉVY, 2011).

A abordagem mais simples do hipertexto é descrevê-lo, em oposição a um texto linear, como um texto estruturado em rede. Sendo assim, o hipertexto é constituído por nós (os elementos de informação, parágrafos, páginas, imagens, sequências musicais etc.) e por links entre esses nós, referências, notas, ponteiros, 'botões' indicando a passagem de um nó a outro (LÉVY, 2010, p. 58).

A informação hipertextual, constituída de elementos tradicionais (parágrafos, páginas, notas de rodapé, etc.) e contemporâneos (nós, links, notas interativas, etc.), facilita a recuperação de obras impressas, eletrônicas e digitais em formatos de livros, vídeos, periódicos (revistas e jornais), páginas web, repositórios institucionais, dentre outros. Em cada tipo de suporte de leitura textual e hipertextual coexistem diferenciados modos de ler e de entender 0 mundo, devendo o leitor estar preparado para utilizar e compreender as variadas modalidades de linguagens comunicadas pelos pares, autores, editores, entre outros atores. A articulação das tecnologias tradicionais e modernas impulsionam processos de produção e de distribuição dos conteúdos informacionais e promovem mudanças nas práticas profissionais e sociais dos consumidores contemporâneos, exigindo a aquisição de saberes e práticas almejadas e alcançadas por sujeitos que se utilizam de serviços e produtos oferecidos por diversas instituições de informação e educação.

As bibliotecas universitárias, escolares e públicas caracterizam-se como espaços tempos de informação e de comunicação que trabalham com 0 oferecimento de práticas de leituras. A promoção da leitura nessas e em outras instituições pode ser apresentada como primordial à dinamização da informação e ao desenvolvimento de competências, principalmente em territórios educativos como a biblioteca e a escola nos quais os sujeitos leitores interagem por meio dos processos de ensino, aprendizagem, busca de informação e contextualização de questões sociais e culturais. Desse modo, os usuários de informação, os gestores, os educadores e "Os bibliotecários devem transformar o ambiente da biblioteca em espaços de aprendizagens e construção de conhecimento" (BEDIN; CHAGAS; SENA, 2015, p. 366). 


\section{METODOLOGIA}

O processo de investigação apresentado assume um caráter descritivo e exploratório tendo como meta a familiarização e a explicitação do cenário desencadeado pela sociedade da informação e do conhecimento, assim como o estabelecimento de relações entre as diversas variáveis propostas pelos objetivos da pesquisa que compreendem o relacionamento das categorias "competência, informação, leitura e letramento" (GIL, 2009).

Em relação aos procedimentos, trata-se de uma pesquisa de cunho bibliográfico que ocasiona na apresentação de "temas" e na explicitação de "direcionamentos" categorizados nos quadros 1, 2, 3, 4, 5 e 6, com a finalidade de colocar em análise um conjunto de habilidades, conhecimentos, técnicas e atitudes necessárias para o desenvolvimento das competências leitora e em informação inter-relacionadas com o processo de letramento. A busca fora realizada em revistas on line produzidas no âmbito da Ciência da Informação e áreas afins de forma que se pudesse recuperar artigos acadêmicos produzidos no século XXI, assim como recorre-se ao contexto das obras de autores que fundamentam questões teóricas necessárias para o processo de análise.

No decorrer da análise apropria-se de aspectos relacionados com modelos direcionados para as competências leitora e em informação cunhados por Cuevas (2008) e Gerlin (2017), explicitando e delineando, desse modo, os seguintes temas e direcionamentos: (a) acesso e uso da informação: gestão de habilidades e estratégias para a compreensão do texto multimodal; (b) uso de diferentes modalidades de leituras: interpretação e compreensão do hipertexto; (c) aprendizado colaborativo do leitor: produção de conhecimento de relevância social; (d) leitura em diversos suportes e linguagens: apropriação da informação textual, sonora e imagética; (e) ação dialógica e colaborativa: construção de práticas e projetos de leituras e (f) uso ético da informação: apropriação ética e legal da informação (hiper)textual. 


\section{RESULTADOS ALCANÇADOS NO DESENVOLVIMENTO DA PESQUISA}

$\mathrm{Na}$ sociedade da informação e do conhecimento mais do que nunca o sujeito encontra-se "[...] inserido em um meio letrado devendo fazer uso da leitura e da escrita de acordo com suas necessidades" (BELLUZZO, 2007, p. 50, grifo do autor), desenvolvendo competências relacionadas com a informação, a leitura e o letramento. Por meio da apresentação dos temas e direcionamentos explicitados a seguir identificam-se conhecimentos, habilidades e atitudes das competências leitora e em informação inteiramente relacionadas com o processo de letramento e, por conseguinte, com a prática da alfabetização comumente conceituada e estudada pela área da Educação.

O tema "Acesso e uso da informação" concebe um direcionamento acerca da "gestão de habilidades e estratégias para a compreensão do texto multimodal" (Quadro 1), ao perceber que o sujeito leitor deverá adquirir habilidades e técnicas tanto para acessar quanto para compreender e interpretar textos alimentados pela escrita e por outros tipos de linguagens: sonora; imagética; gráfica; gestual; etc.

\section{Quadro 1 - Tema e direcionamento para o acesso da informação textual.}

\begin{tabular}{|c|c|c|}
\hline & & \\
\hline $\begin{array}{l}\text { COMPETÊNCIA } \\
\text { LEITORA }\end{array}$ & ALFABETIZAÇÃO E LETRAMENTO & $\begin{array}{l}\text { COMPETÊNCIA } \\
\text { INFORMAÇÃO }\end{array}$ \\
\hline $\begin{array}{l}\text { - Acesso, avaliação e } \\
\text { uso da informação } \\
\text { textual com contextos } \\
\text { diferenciados; } \\
\text {-Conhecimento de } \\
\text { técnicas e estratégias } \\
\text { de leitura (seleção, } \\
\text { análise, inferência, } \\
\text { síntese, etc.); } \\
\text {-Compreensão e } \\
\text { interpretação de textos } \\
\text { multimodais pela } \\
\text { alimentados multimodal } \\
\text { linguagem muarara, sonora, } \\
\text { (escrita, gráfica, } \\
\text { imagética, gestual, etc.). }\end{array}$ & $\begin{array}{l}\text { - Conhecimento do sistema } \\
\text { convencional da escrita (aquisição do } \\
\text { código), assim como, decodificação } \\
\text { dos códigos da leitura; } \\
\text {-Compreensão dos códigos que } \\
\text { possibilitam o domínio da língua } \\
\text { escrita e oral abrangendo o } \\
\text { reconhecimento das letras e dos } \\
\text { sons; } \\
\text {-Aprendizagem significativa do } \\
\text { sistema da escrita e da leitura } \\
\text { relacionado com o contexto social do } \\
\text { leitor; } \\
\text {-Capacidade para apreciar e julgar a } \\
\text { informação, ao adquirir habilidade } \\
\text { reflexiva acerca da informação } \\
\text { recuperada em espaços presenciais e } \\
\text { virtuais. }\end{array}$ & $\begin{array}{l}\text {-Domínio das ferramentas de } \\
\text { busca e recuperação da } \\
\text { informação; } \\
\text {-Consulta aos catálogos } \\
\text { manuais e digitais e domínio } \\
\text { de acesso às redes digitais e } \\
\text { aos acervos presenciais, etc.; } \\
\text {-Localização e avaliação de } \\
\text { informações (hiper)textuais; } \\
\text {-Conhecimento sobre o } \\
\text { manuseio de equipamentos } \\
\text { (não) eletrônicos; } \\
\text {-Busca, recuperação e } \\
\text { acesso da informação textual } \\
\text { por meio das novas } \\
\text { tecnologias de escrita, } \\
\text { informação e comunicação. }\end{array}$ \\
\hline
\end{tabular}

Fonte: Dados da pesquisa. 
Dotado de competências no âmbito da leitura e da informação o leitor necessitará compreender o texto recuperado e analisar criticamente a veracidade das informações que posteriormente serão utilizadas. Enquanto a competência em informação fornece a capacitação necessária em um processo de busca e recuperação, permitindo uma utilização eficiente e eficaz dos recursos informacionais, a competência leitora intensifica o conhecimento de estratégias para o entendimento do texto e do hipertexto acessado.

O processo de busca e recuperação da informação pode ser conceituado como o processo de localizar documentos e itens de informação que tenham sido objeto de armazenamento, com a finalidade de permitir o acesso dos usuários aos itens de informação, objetos de uma solicitação (ARAÚJO JÚNIOR, 2007, p. 65).

$O$ ato de localizar a informação representada em catálogos de bibliotecas virtuais ou em outras base de dados on line, requisita o desenvolvimento das competências leitora em em informação para selecionar e, posteriormente, compreender diversos tipos de textos (narrativos, dissertação, descrição, exposição, etc.) e hipertextos (informação remissiva e interligada com textos, palavras, imagens, sons, etc.).

Percebe-se que os conhecimentos (saberes) e as habilidades (fazeres) que giram em torno do acesso e da compreensão da informação devem ser garantidas para o sucesso dos processos de busca, recuperação e uso efetivo do texto informativo, literário e/ou outros. Desse modo, o sujeito leitor necessitará autonomamente, ou com o auxílio de um profissional da informação, adquirir conhecimentos acerca do funcionamento dos "[...] sistemas de recuperação da informação [que] podem ser entendidos como um conjunto de regras e procedimentos executados a partir da ação humana e/ou máquinas" (ARAÚJO JÚNIOR, 2007, p. 73), de forma que consiga trabalhar com a:

- Formulação da busca: elaboração de questões precisas que devem representar as lacunas relacionadas com as necessidades informacionais internas e externas;

- Busca: confrontação de questões formuladas com representações dos conteúdos de informação que conduzem à utilização de ferramentas apropriadas visando sanar as necessidades de informação; 
- Retroalimentação: ação também conhecida como feedback que acontece por meio da repetição das operações e/ou modificações introduzidas nas respostas, a fim de avaliar os resultados dos processos de buscas relacionados com a recuperação da informação.

Profissionais da informação, como bibliotecários, arquivistas e museólogos, detêm conhecimentos relacionados com as atividades de indexação (construção e representação de conteúdos) e construção de linguagens de indexação (geração de regras de representação), auxiliando no processo de recuperação em sistemas de informação, manuais ou automatizados, organizados para armazenar e disseminar informações, como os catálogos em linha, a própria internet e os sistemas de gerenciamento de documentos (ARAÚJO JÚNIOR, 2007).

Os processos de busca e de compreensão exigem a articulação do conhecimentos do sistema convencional da escrita relacionados com o contexto social, sendo adquiridos por meio da alfabetização e do letramento. Soares (2004, p. 98) disserta sobre os métodos da prática da alfabetização dividindo-os em dois grupos. "Em ambas as opções, porém, a meta sempre foi a aprendizagem do sistema alfabético e ortográfico da escrita; embora se possa identificar, na segunda opção, uma preocupação também com o sentido veiculado pelo código [...]" da escrita e da leitura:

- Síntese: parte de unidades menores da língua (os fonemas, as sílabas em direção às unidades maiores: a palavra, a frase, o texto) ao utilizar o método fônico e o método silábico;

- Análise: parte das unidades maiores e portadoras de sentido (a palavra, a frase, o texto em direção às unidades menores) ao utilizar o método da palavração, o método da sentenciação e o método global.

Enquanto a prática da alfabetização preocupa-se com o conhecimento do sistema convencional da escrita e com a aquisição do código, o processo de letramento abrange necessidades de grupos letrados e iletrados, dotando-os de condição para interagir com o meio social por meio da apropriação da linguagem oral, escrita e imagética (multimodal). A prática da leitura fortalecida pelas 
tecnologias de informação e comunicação permite utilizar "[...] a tela como espaço de escrita e de leitura [que] traz não apenas novas formas de acesso à informação, mas também novos processos cognitivos, novas formas de conhecimento, novas maneiras de ler e de escrever, enfim, um novo letramento" (SOARES, 2002, p. 152).

Ao gerir um conjunto de habilidades, técnicas e atitudes que possibilitam o acesso e o uso da informação multimodal com o auxílio das novas tecnologias (BELLUZZO, 2007), o sujeito obterá conhecimentos sobre como manusear equipamentos eletrônicos ao se munir de estratégias de leitura direcionadas para a seleção, análise, inferência e síntese para, em seguida, saber avaliar e interpretar o (con)texto informativo, literário e/ou técnico recuperado. Nesse sentido, o tema "Uso de diferentes modalidades de leituras" conduz ao direcionamento sobre as diversas formas de "interpretação e compreensão do hipertexto" (Quadro 2).

\section{Quadro 2 - Tema e direcionamento para o uso de diferentes modalidades de leituras.}

\begin{tabular}{|c|c|c|}
\hline \multicolumn{3}{|c|}{ Uso de diferentes modalidades de leituras: interpretação e compreensão do hipertexto } \\
\hline COMPETÊNCIA LEITORA & $\begin{array}{l}\text { ALFABETIZAÇÃO } \\
\text { LETRAMENTO }\end{array}$ & $\begin{array}{l}\text { COMPETÊNCIA } \\
\text { INFORMAÇÃO }\end{array}$ \\
\hline $\begin{array}{l}\text {-Compreensão de diversas } \\
\text { modalidades por meio da } \\
\text { mobilização de processos de } \\
\text { leituras que perpassam a } \\
\text { necessidade, o interesse e o } \\
\text { prazer; } \\
\text { - Habilidade de interpretação } \\
\text { do (hiper)texto } \\
\text { disponibilizado da página do } \\
\text { livro à tela do computador ou } \\
\text { de outro equipamento } \\
\text { eletrônico; do do contexto } \\
\text {-Conhecimento do } \\
\text { do texto e do hipertexto digital } \\
\text { para um uso efetivo da } \\
\text { informação oralizada, escrita, } \\
\text { auditiva, etc. }\end{array}$ & $\begin{array}{l}\text {-Apropriação de diversos tipos } \\
\text { de textos, informativos ou } \\
\text { literários por meio da prática da } \\
\text { alfabetização; } \\
\text {-Mobilização de uma leitura } \\
\text { crítica que envolve a aquisição } \\
\text { do código de diversas } \\
\text { linguagens (texto com contexto); } \\
\text {-Habilidade para processar } \\
\text { informações simbólicas e } \\
\text { proficiência no ato de falar, ler e } \\
\text { escrever; } \\
\text {-Desenvolvimento do letramento } \\
\text { por meio da habilidade técnica } \\
\text { de como saber ler o (con)texto } \\
\text { ao agregar valor por meio da } \\
\text { produção de conhecimento. }\end{array}$ & $\begin{array}{l}\text {-Conhecimento de como } \\
\text { usar recursos de leituras } \\
\text { digitais e eletrônicos ao } \\
\text { navegar no ciberespaço } \\
\text { e/ou buscar informação } \\
\text { em contextos presenciais; } \\
\text {-Autonomia nos } \\
\text { processos de busca, } \\
\text { seleção e avaliação que } \\
\text { acarretam na leitura e no } \\
\text { uso efetivo da informação; } \\
\text {-Aplicação da informação } \\
\text { recuperada perante o } \\
\text { contexto social do seu uso } \\
\text { efetivo; } \\
\text { - Uso coletivo ou individual } \\
\text { da informação textual e/ou } \\
\text { hipertextual. }\end{array}$ \\
\hline
\end{tabular}

Fonte: Dados da pesquisa.

Os processos de busca e de recuperação da informação textual e hipertextual devem estar em consonância com a necessidade do uso das diferentes modalidades de leitura (técnica, lúdica, informativa, literária, etc.), 
precisando o sujeito leitor demonstrar interesse e/ou necessidade por aquilo que é desejado e/ou conhecido ao navegar no ciberespaço e/ou recuperar informações no espaço presencial. $O$ uso propriamente dito de um recurso informativo requer habilidade para a interpretação durante a leitura de um texto multimodal e a compreensão de um novo contexto de leitura disponibilizado pelos hipertextos digitais. Lévy (2011, p. 44) expõe que "[...] o hipertexto digital seria portanto definido como uma coleção de informações multimodais disposta em rede para a navegação rápida e 'intuitiva'”.

Entende-se que "A apreensão da informação presume a habilidade das pessoas para decodificar e processar informações simbólicas e de proficiência no [ato de] falar, ler e escrever" desde o acesso da página de um livro impresso até a tela de um computador e/ou de outro equipamento eletrônico (VARELA; BARBOSA; FARIAS, 2017, p. 282). Para tanto, o desenvolvimento das competências leitora e em informação solicitam a mobilização de uma leitura crítica que perpassa o repertório cultural do usuário de informação, bem como habilidades e conhecimentos para a interpretação e a compreensão de (hiper)textos (utiliza-se esse termo para referenciar o texto e o hipertexto sem hierarquizações e ordem de importância).

A aquisição de estratégias para uma leitura crítica envolve o respeito aos diferentes repertórios culturais e visões de mundo do leitor (FREIRE, 1996), sendo esse sujeito considerado como "Alguém capaz de analisar e discutir informações racionalmente, com perspicácia e discernimento, [...] dotado de senso crítico, com atitude de permanente curiosidade intelectual e indagação [...]" (VARELA; BARBOSA; FARIAS, 2017, p. 282). Para isso, torna-se necessário que o letramento promova o protagonismo social e a autonomia no que se refere, principalmente, aos processos individuais e coletivos de seleção e avaliação direcionados para um uso efetivo da informação (hiper)textual e para uma posterior aplicação social.

O protagonismo social se caracteriza como elemento fundante do processo democrático de construção das bases de humanização do mundo e, o efetivo desenvolvimento desse protagonismo se dá com o apoio das atividades de mediação consciente da informação, o que implica conhecimento do que seja informação, da sua missão social, das dimensões da 
mediação e da força dessa ação também protagonista" (GOMES, 2019, p. 19).

A apropriação das novas tecnologias devem ocasionar em aprendizagens colaborativas, ao culminar em processos de formações e ações específicas relevantes. O tema "Aprendizado colaborativo do leitor" encontra-se ligado ao direcionamento sobre a "produção de conhecimento de relevância social" (Quadro 3), consubstanciando-se perante a capacidade de o sujeito interagir culturalmente e socialmente com seus pares, autores, editores, professores, agentes culturais, bibliotecários e outros protagonistas da sociedade contemporânea.

A proposição de atividades colaborativas acabam requerendo um direcionamento para a aquisição de habilidades e técnicas que possam garantir ações de escrita e leitura crítica em espaços tempos de informação e cultura como a biblioteca comunitária, municipal e pública. "Assim, a leitura e escrita são, na contemporaneidade, ferramentas decisivas para que os atores sociais possam desenvolver de maneira plena seu potencial humano (CAVALCANTE; RASTELI, 2013, p. 164). Destaca-se a importância do desenvolvimento de práticas de leituras em outros tipos de bibliotecas que também tenham como missão capacitar o usuário em processos colaborativos de busca, recuperação e compreensão do (hiper)texto.

Quadro 3 - Tema e direcionamento para um aprendizado colaborativo

\begin{tabular}{|c|c|c|}
\hline $\begin{array}{l}\text { ETÊNCIA } \\
\text { RA }\end{array}$ & $\begin{array}{l}\text { ALFABETIZAÇÃO } \\
\text { LETRAMENTO }\end{array}$ & $\begin{array}{l}\text { COMPETÊNCIA } \\
\text { INFORMAÇÃO }\end{array}$ \\
\hline $\begin{array}{l}\text {-Desenvolvimento de } \\
\text { atividades de leituras } \\
\text { relevantes aplicadas no } \\
\text { contexto social do leitor; } \\
\text {-Capacidade de interagir } \\
\text { culturalmente er outros } \\
\text { socialmente com por meio de ações } \\
\text { sujeitos por me de } \\
\text { que envolvem práticas de } \\
\text { leituras; Aprendizagens } \\
\text { - significativas por meio das } \\
\text { leituras e das conexões } \\
\text { dos sujeitos leitores em } \\
\text { redes sociais e digitais. }\end{array}$ & $\begin{array}{l}\text {-Obtenção de sucesso } \\
\text { das demandas individuais } \\
\text { e sociais perante a } \\
\text { apropriação do código da } \\
\text { escrita e da leitura; } \\
\text {-Motivação, atitudes, } \\
\text { emoções e outros } \\
\text { componentes sociais que } \\
\text { conduzem ao processo de } \\
\text { letramento; } \\
\text {-Conhecimento de como } \\
\text { saber aplicar o conteúdo } \\
\text { textual buscado e } \\
\text { recuperado no contexto } \\
\text { social do leitor. }\end{array}$ & $\begin{array}{l}\text { - Habilidades de busca na tela dos } \\
\text { equipamentos eletrônicos e em } \\
\text { obras impressas; } \\
\text {-Apropriação das novas tecnologias } \\
\text { que conduzam ao exercício de } \\
\text { práticas colaborativas de leitura e } \\
\text { de escrita; } \\
\text {-Conexão em redes e } \\
\text { participação/interação efetiva num } \\
\text { ambiente híbrido (presencial e } \\
\text { virtual). } \\
\text { - Técnicas que conduzam ao } \\
\text { processos de busca e recuperação } \\
\text { em diferentes suportes a fim } \\
\text { possibilitar o uso e a produção de } \\
\text { conhecimento de relevância social. }\end{array}$ \\
\hline
\end{tabular}

Fonte: Dados da pesquisa. 
Todavia, as ações que ocasionam em um aprendizado colaborativo precisam partir dos sujeitos que atuam em ambientes como as bibliotecas, porém não se encerrando nelas. De maneira geral, devem conduzir a um aprendizado ao longo da vida por meio do atendimento de demandas individuais e coletivas em uma variedade de espaços presenciais e virtuais. Desse modo, desenvolvendo "[...] ações de apoio à leitura a biblioteca não apenas auxilia os usuários a ampliar suas habilidades e competências na leitura enquanto técnica, que possibilita a decodificação de uma informação em determinado material" (GOMES; SANTOS, 2014, 260), mas também prepara o sujeito leitor para produzir conhecimento de relevância social na medida em que se torna protagonista na era digital.

As competências leitora e em informação solicitam um saber fazer voltado para a formação de usuários leitores e, por conseguinte, para o encaminhamento de ações colaborativas que sejam aplicadas em diversos contextos da vida social, profissional, escolar, acadêmica, etc. As ações colaborativas devem culminar em aprendizagens significativas por meio das leituras e das conexões dos sujeitos leitores em redes sociais e digitais (CASTELLS, 2011) que possibilitam processos de recuperação, uso e (re)produção da informação, requerendo o desenvolvimento de atividades e programas de competências para a aplicação de planejamento de ações no campo da leitura e da informação em diversos contextos.

O tema "Leitura em diversos suportes e linguagens" direciona-se para a "apropriação da informação textual, sonora e imagética" (Quadro 4), perpassando a experimentação de uma estrutura que possibilita a busca, a recuperação e o acesso às leituras disponibilizadas em espaços presenciais, virtuais e/ou híbridos. Com o acesso aos diferentes suportes de informação e uma integração cotidiana com o ciberespaço, percebe-se que "[...] os formatos impressos estão sendo cada vez mais substituídos por textos virtuais [...], que introduzem múltiplas possibilidades nas práticas de leitura, fornecendo um cenário complexo de diferentes linguagens" (CAVALCANTE; RASTELI, 2013, p. 166). 


\section{Quadro 4 - Temas e direcionamento para a leitura em diferentes suportes}

\begin{tabular}{|c|c|c|}
\hline \multicolumn{3}{|c|}{$\begin{array}{l}\text { Leitura em diversos suportes e linguagens: apropriação da informação textual, sonora e } \\
\text { imagética }\end{array}$} \\
\hline $\begin{array}{l}\text { COMPETÊNCIA } \\
\text { LEITORA }\end{array}$ & $\begin{array}{l}\text { ALFABETIZAÇÃO } \\
\text { LETRAMENTO }\end{array}$ & $\begin{array}{l}\text { COMPETÊNCIA } \\
\text { INFORMAÇÃO }\end{array}$ \\
\hline $\begin{array}{l}\text {-Apropriação da da } \\
\text { informação textual, } \\
\text { sonora e imagética em } \\
\text { diversos suportes de } \\
\text { leituras; } \\
\text { - Utilização de } \\
\text { habilidades e técnicas } \\
\text { que possibilitem a leitura } \\
\text { (hiper)textual; } \\
\text {-Estabelecimento de } \\
\text { contato com uma } \\
\text { estrutura de leitura tanto } \\
\text { no espaço presencial } \\
\text { quanto no ciberespaço. }\end{array}$ & $\begin{array}{l}\text {-Integração com os códigos de uma } \\
\text { linguagem cotidiana com a } \\
\text { linguagem do espaço presencial e } \\
\text { virtual; } \\
\text {-Experimentação de uma estrutura } \\
\text { de leitura dependente de processos } \\
\text { de alfabetização e letramento que } \\
\text { conduz o leitor ao hipertexto } \\
\text { (letramento e espaço digital); } \\
\text {-Atitudes direcionadas para o } \\
\text { relacionamento social requerido em } \\
\text { processos de uso, compreensão e } \\
\text { compartilhamento dos conteúdos } \\
\text { (hiper)textuais. }\end{array}$ & $\begin{array}{l}\text {-Habilidades de acesso à } \\
\text { informações em Wikis; } \\
\text { Chats; Fóruns; etc. } \\
\text {-Compartilhamentos da } \\
\text { informação textual, sonora } \\
\text { e imagética em blogs; Web } \\
\text { sites; Redes; etc. } \\
\text {-Domínio de conhecimentos } \\
\text { para a busca e a } \\
\text { recuperação em bancos de } \\
\text { dados de bibliotecas } \\
\text { virtuais; banco de Imagens; } \\
\text { rede de compartilhamento } \\
\text { de imagens, etc. }\end{array}$ \\
\hline
\end{tabular}

Fonte: Dados da pesquisa

O desenvolvimento de habilidades, conhecimentos e atitudes necessárias para se apropriar autonomamente de diferentes conteúdos textuais, sonoros e imagéticos é extremamente necessário, assim como aprender a aprender a estabelecer contato de maneira independente com uma estrutura de leitura hipertextual disponibilizada pela web/internet; já que "A abertura da arquitetura da Internet foi a fonte de sua principal força: seu desenvolvimento autônomo, à medida que usuários tornam-se produtores da tecnologia e artífices de toda rede" (CASTELLS, 2003, p. 28).

O sujeito autossuficiente desenvolverá competências para acessar informações (hiper)textuais disponibilizados em ambientes como wikis, blogs, bancos de dados/imagens de bibliotecas digitais e outros ambientes não citados, a fim de obter 0 acesso aos itens de informação digitalizados em linguagens textual, sonora, imagética, etc. A importância que é dada a contribuição da biblioteca em contextos híbridos é referenciada juntamente com o potencial da disseminação da informação no contexto da universidade, estando fortemente direcionada com a mediação da informação e o acesso aos suportes impressos, eletrônicos e digitais.

Entende-se que a mediação da informação está diretamente ligada às ações implícitas e explícitas, voltadas para o usuário, e que a mesma é fundamental nas práticas do profissional da 
informação. O caráter da mediação depende não somente das ações realizadas pelos bibliotecários, como também da presença imediata/física ou não dos usuários (ALMEIDA JUNIOR; SANTOS NETO, 2014, p. 101-102)".

Entre os serviços e produtos oferecidos na biblioteca universitária destaca-se a expansão do processo de mediação em um serviço de referência que fora fortemente fortalecido pelo atendimento virtual e, consequentemente, pela área da Tecnologia da Informação (ARAÚJO JÚNIOR, 2007). A biblioteca da universidade, desse modo, [...] se posiciona como um ambiente de apoio à formação dos usuários. Para tanto, ela organiza e proporciona a recuperação, acesso e uso das informações [...] para a ampliação das competências e habilidades de seus usuários" (GOMES; SANTOS, 2014, p. 258). A mediação da informação, cultural e da leitura encontram-se relacionadas em ambientes presenciais, virtuais e híbridos como a biblioteca universitária e outras unidades de informação, devido ao fato de que

O processo interacionista, colaborativo e de compartilhamento, implica em várias ações de mediação, e dentre elas a própria mediação da informação. Mediadores e dispositivos de mediação são articulados e atuam como elementos importante ao [ato de] conhecer (GOMES, 2019, p. 19).

A criação de práticas culturais e educativas no âmbito da informação e da leitura conduzem ao tema "Ação dialógica e colaborativa" ligado ao direcionamento da "construção de práticas e projetos de leituras" (Quadro 5). Esse direcionamento solicita competências leitora e em informação que consubstanciam práticas relacionadas com o senso crítico, a criatividade e a curiosidade por meio do processo de letramento. Exige o planejamento de estratégias educativas relevantes em variados níveis sociais (ASSMANN, 2000), para o desenvolvimento das habilidades, técnicas e atitudes relacionadas com um saber fazer voltado para a utilização de informações buscadas e avaliadas para agregar valor à prática de elaboração de projetos direcionados para a coletividade. 


\section{Quadro 5 - Tema e direcionamento para a construção de práticas e projetos de leituras.}

\begin{tabular}{|c|c|c|}
\hline $\begin{array}{l}\text { COMPETÊNCIA } \\
\text { LEITORA }\end{array}$ & ALFABETIZAÇÃO E LETRAMENTO & $\begin{array}{l}\text { COMPETÊNCIA } \\
\text { INFORMAĈ̃O }\end{array}$ \\
\hline 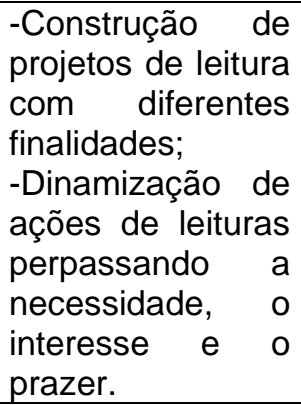 & $\begin{array}{l}\text { - Comportamentos e práticas da área da } \\
\text { leitura e da escrita aplicadas ao } \\
\text { contexto social; } \\
\text {-Desenvolvimento do senso crítico, } \\
\text { criatividade e curiosidade por meio do } \\
\text { letramento; } \\
\text {-Trabalho com atividades de promoção } \\
\text { da leitura que exijam a materialização } \\
\text { de projetos dialógicos que possam } \\
\text { gerar retorno para a coletividade. }\end{array}$ & $\begin{array}{l}\text {-Desenvolvimento das } \\
\text { competências de localizar, } \\
\text { avaliar e utilizar informações } \\
\text { agregando valor no processo } \\
\text { de elaboração de projetos; } \\
\text {-Capacidade de resolver } \\
\text { problemas perante a proposta } \\
\text { de novas arquiteturas de } \\
\text { processos de busca e } \\
\text { recuperação da informação. }\end{array}$ \\
\hline
\end{tabular}

Fonte: Dados da pesquisa.

A implantação de projetos de leitura é uma estratégia adotada em diferentes ambientes comprometidos com a mediação da informação e com a formação dos leitores. Diante desse contexto, as bibliotecas escolares e públicas apresentam-se como espaços de mediação da informação e cultural que procura criar oportunidades para aprendizagens significativas por meio do oferecimento de projetos de leituras. Tendo em vista que o leitor contemporâneo "[...] na atualidade, já nasceu em uma era digital e utiliza com frequência as tecnologias [... é necessário] que haja um maior dinamismo, e principalmente, um maior interesse pelo espaço da biblioteca" (BEDIN; CHAGAS; SENA, 2015).

O planejamento e a ação cultural, desse modo, são ferramentas constantemente utilizadas em bibliotecas escolares, comunitárias, municipais e públicas com a finalidade de alcançar públicos diferenciados de maneira dinâmica em uma era de intensificação do uso das novas tecnologias. Devido a missão de formar leitores por meio do oferecimento de práticas de leituras que envolvam a comunidade interna e externa, os projetos culturais nesses espaços costuma alcançar variados tipos de sujeitos leitores.

A ação cultural envolve a participação dos sujeitos envolvidos na atividade cultural desde a elaboração de um planejamento até a sua implantação, com etapas flexibilizadas e alteradas durante todo o processo de oferecimento de um projeto ou serviço [... ao] provocar algum tipo de transformação, o que necessariamente não acontece em um momento de animação cultural" (GERLIN, 2018, p. 60).

Dada as diferenças que a era da informação apresenta cabe ao mediador 
e aos leitores desenvolverem eticamente o senso crítico em articulação com a criatividade, ao oferecer práticas de leituras com diferentes finalidades por meio da ação cultural, já que "Os participantes assumem uma função ativa no decorrer das ações e, para além da diversão, no processo de construção a atividade cultural possibilita práticas reflexivas que podem gerar importantes transformações" (GERLIN, 2018, p. 62). Uma atividade fundamentada na ação cultural deve se constituir como um processo planejado sem etapas intermediárias e finais. Deve se concretizar de maneira flexível ao envolver usuários, gestores culturais, bibliotecários, professores e demais sujeitos interessados em participar dos projetos, tendo em vista que

\begin{abstract}
A ação cultural se reflete para o bibliotecário [e para o público leitor] como estímulo para a aquisição de competências, saberes, fazeres e compartilhamento de experiências que potencializem suas capacidades de atuação como mediador de leitura" (CAVALCANTE; RASTELI. 2013, p. 169).
\end{abstract}

A apropriação e o uso da informação solicita o desenvolvimento das competências em informação e leitora, requerendo práticas relacionadas com processos de busca, recuperação e compartilhamento ético da informação. Assim sendo, o tema "Uso ético da informação" encontra-se ligado ao direcionamento da "apropriação ética e legal da informação (hiper)textual" (Quadro 6), colocando em questão a legalidade da interpretação da informação textual e hipertextual relacionada com a necessidade de uma utilização responsável. O sujeito leitor, deve, para isso, aprender a citar os autores e as obras consultadas, reconhecendo a propriedade intelectual e os direitos autorais dos itens de informação recuperados em ambientes como bibliotecas, repositórios e base de dados presenciais, virtuais e/ou híbridos.

Quadro 6 - Tema e direcionamento para o uso ético da informação.

\begin{tabular}{|c|c|c|}
\hline $\begin{array}{l}\text { COMPETÉNCIA } \\
\text { LEITORA }\end{array}$ & $\begin{array}{l}\text { ALFABETIZAÇÃO } \\
\text { LETRAMENTO }\end{array}$ & $\begin{array}{l}\text { COMPETÊNCIA } \\
\text { INFORMAÇÃO }\end{array}$ \\
\hline $\begin{array}{l}\text { - Planejamento de ações e } \\
\text { projetos eticamente } \\
\text { comprometidos com a } \\
\text { prática leitora; } \\
\text {-Comprometimento com } \\
\text { preceitos éticos durante a } \\
\text { realização de atividades } \\
\text { no âmbito da leitura em } \\
\end{array}$ & $\begin{array}{l}\text {-Desenvolvimento de atividades } \\
\text { que exigem a articulação do } \\
\text { código da escrita e da leitura } \\
\text { com o uso ético da informação } \\
\text { (hper)textual; } \\
\text {-Geração de retorno para a } \\
\text { coletividade por meio da } \\
\text { apropriação crítica e da }\end{array}$ & $\begin{array}{l}\text {-Orientação ao leitor sobre o } \\
\text { uso ético dos recursos } \\
\text { informacionais; } \\
\text {-Conhecimento do uso das } \\
\text { normas de elaboração de } \\
\text { referências, citações de } \\
\text { autoria, trabalhos } \\
\text { acadêmicos e projetos; }\end{array}$ \\
\hline
\end{tabular}




\begin{tabular}{|c|c|c|}
\hline $\begin{array}{l}\text { espaços de informação e } \\
\text { educação; } \\
\text {-Citação de autores e } \\
\text { obras consultadas ao } \\
\text { reconhecer os direitos dos } \\
\text { autores dos (hiper)textos. }\end{array}$ & $\begin{array}{l}\text { conscientização acerca do usc } \\
\text { ético da informação; } \\
\text {-Apropriação, uso } \\
\text { compartilhamento ético de } \\
\text { informação em processos de } \\
\text { letramento. }\end{array}$ & $\begin{array}{l}\text {-Desenvolvimento } r \text { de } \\
\text { habilidades e técnicas } \\
\text { relacionadas com questões } \\
\text { éticas em processos de } \\
\text { busca, recuperação, uso da } \\
\text { informação. }\end{array}$ \\
\hline
\end{tabular}

Fonte: Dados da pesquisa.

Cabe aos usuários da informação, bibliotecário e demais educadores atuarem coletivamente na construção de espaços de formações, contribuindo para que a autoria dos textos consultados seja respeitada em ambientes acadêmicos, escolares e colaborativos como o ciberespaço. Para tanto, deve-se conhecer leis que protegem os direitos do autor e que consolidam a legislação sobre direitos autorais, penalizando o uso indevido de material intelectual sem a devida indicação de autoria (BRASIL, 1998). Também é necessário aprender a usar normas técnicas subjacentes ao uso e compartilhamento apropriado dos recursos (hiper)textuais. "A normalização é uma forma de garantir a autoridade das fontes consultadas para a elaboração de um trabalho científico [dentre outras modalidades], e seu tratamento correto evita questões como plágio e omissão de autoria" (GULKA; LUCAS, 2018, p. 229).

Ao recorrer às normas que padronizam a elaboração de referências, citações de autoria, trabalhos acadêmicos e projetos compreende-se, portanto, que a realidade imposta pela sociedade da informação e do conhecimento permite considerar que os conceitos que giram em torno da competência, da informação e da leitura estão inteiramente relacionados com as práticas de construção de projetos de leitura demandando um uso ético da informação. Por conseguinte, as pesquisas no campo da Ciência da Informação e áreas afins como a Educação e a Tecnologia de Informação, devem colocar em análise aspectos pertinentes às competências relacionadas com o desenvolvimento de ações no âmbito do letramento em diversos espaços de educação, informação e cultura.

A biblioteca, a escola, a universidade e o ciberespaço são ambientes de interação social e de aprendizagens dentro de um contexto de (in)formação, devendo se comprometer com processos de capacitação de multiplicadores conectados em redes colaborativas. Torna-se, portanto, cada vez mais 
importante trabalhar com ações que desencadeiam competências leitora e em informação em diferentes espaços como as bibliotecas comunitárias, escolares, públicas e universitárias. A biblioteca deve, portanto, ser entendida como um centro de formação responsável pelo compartilhamento da informação e formação no âmbito dessas competências, ao considerar as necessidades informacionais relacionadas com aprendizagens necessárias para a inserção do sujeito leitor na era digital.

\section{CONSIDERAÇÕES QUE (NÃO) SÃO FINAIS}

O desenvolvimento da pesquisa aponta para a necessidade de continuação da investigação acerca dos temas trabalhados, tendo em vista que a sociedade da informação e do conhecimento solicita cotidianamente competências compreendidas no campo da informação e da leitura que dependam da combinação de habilidades (saber fazer), conhecimentos (saber ser) e atitudes (saber agir), requerendo igualmente a aquisição de habilidades cognitivas e técnicas relacionadas com a escrita e com a leitura no âmbito da alfabetização, juntamente com a mobilização de práticas socialmente constituídas durante o processo de letramento na era digital.

As categorias apresentadas nos quadros e identificadas por meio da literatura da Ciência da Informação e áreas afins, conduzem ao delineamento de direcionamentos relacionados com as competências leitora e em informação, indicando um inter-relacionamento necessário com o processo de letramento. Conduz, portanto, ao questionamento acerca da qualidade do acesso das várias modalidades de leituras e sobre o desenvolvimento da capacidade de compreensão e apropriação das diversas modalidades de suportes textuais impressos, eletrônicos e digitais.

O conjunto de temas e direcionamentos que giram em torno do aprendizado autônomo e colaborativo, permite compreender que essas competências facilitam processos de busca, recuperação, seleção e acesso de variadas modalidades de leituras alimentadas por linguagens multimodais; solicitando que a capacidade de compreensão dos (hiper)textos seja 
efetivamente alcançada por um usuário de informação letrado minimizando, desse modo, as desigualdades sociais. Percebe-se que por meio do exercício de uma leitura crítica torna-se possível a construção de práticas e projetos de leituras relacionadas com o uso ético da informação, dependendo de uma combinação de conhecimentos e atitudes sociais numa era da informação em que se intensifica a conexão em redes no ciberespaço.

Perante a amplitude da mediação da informação e das práticas de leituras, percebe-se a necessidade do desenvolvimento de habilidades, técnicas e atitudes necessárias para a obtenção do sucesso de demandas individuais e coletivas, solicitando a implementação de programas e ações voltadas para as competências leitora e em informação em bibliotecas, escolas, comunidades, ciberespaço, universidades, dentre outros espaços tempos. Nesse sentido, verifica-se que os programas de competências acabam requerendo o uso das ferramentas de planejamento, ações culturais e educativas que visam 0 desenvolvimento de conhecimentos e capacidades necessárias para buscar, recuperar, avaliar, usar, compreender e compartilhar informações textuais relevantes para o contexto social do leitor ao longo da atuação escolar, acadêmica, profissional, comunitária e em outros estágios de aprendizagens colaborativas.

\section{REFERÊNCIAS}

ALMEIDA JUNIOR, O. F.; SANTOS NETO, J. A. Mediação da informação e a organização do conhecimento: interrelações. Informação \& Informação, v. 19, n. 2, p. 98-116, 2014.

ASSMANN, H. A metamorfose do aprender na sociedade da informação. Ciência da Informação, Brasília, v. 29, n. 2, p. 7-15, maio/ago. 2000.

ARAÚJO JÚNIOR, R. H. Precisão no processo de busca e recuperação da informação. Brasília: Thesaurus, 2007.

BEDIN, J.; CHAGAS, M. T.; SENA, P. M. B. Competência informacional em biblioteca escolar: ações para o desenvolvimento. Revista ACB: Biblioteconomia em Santa Catarina, v. 20, n. 3, p. 363-372, 2015.

BELLUZZO, R. C. B. Construção de mapas: desenvolvendo competências em informação e comunicação. Bauru, São Paulo: Cá Entre Nós, 2007. 
BELLUZZO, R. C. B.; FERES, G. G. Competência em informação, redes de conhecimento e as metas educativas para 2021: reflexões e inter-relações. In: BELLUZZO, Regina Célia Baptista; FERES, Glória Georges; VALETIM, M. L. P. (Org.). Redes de conhecimento e competência em informação. Rio de Janeiro: Interciência, 2015.

BRASIL. Lei n. 9.610, de 19 de fevereiro de 1998. Altera, atualiza e consolida a legislação sobre direitos autorais e dá outras providências. Diário Oficial da União, Brasília, n. 36, seção 1, 20 fev. 1998.

CAPURRO, R.; Hjorland, B. O conceito de informação. Perspectivas em Ciência da Informação, Belo Horizonte, v. 121, n. 1, p. 148-207, jan./abr. 2007.

CASTELLS, M. A galáxia da internet: reflexões sobre a internet, os negócios e a sociedade. Rio de Janeiro: Jorge Zahar Ed., 2003.

CASTELLS, M. A Sociedade em rede: a era da Informação: economia, sociedade e cultura. São Paulo: Paz e Terra, 2011.

CAVALCANTE, L. E.; RASTELI, A. A competência em informação e o bibliotecário mediador da leitura em biblioteca pública. Encontros Bibli: Revista Eletrônica de Biblioteconomia e Ciência da Informação, v. 18, n. 36, p. 157180, 2013.

CUEVAS, A. Competencia lectora y alfabetización en información: un modelo para La biblioteca escolar en la sociedad del conocimiento. Revista Iberoamericana de Ciência da Informação (RICl), Brasília, v.1, n.1, p.3-20, jan./jun. 2008.

FREIRE, P. A importância do ato de ler: três artigos que se completam. São Paulo: Cortez, 1996.

GERLIN, M. N. M. Produção de competência leitora em espaços tempos de informação, educação e cultura. In: Seminário Hispano Brasileño: Investigación em información, documentación y sociedade, 2017, Aracajú, SE. Anais eletrônicos... Aracajú, SE: EDUNIT, 2017.

GERLIN, M. N. M. Tecendo redes e contando histórias: competências em informação e narrativa na contemporaneidade. Brasília: Faculdade de Ciência da Informação, Universidade de Brasília, 2018. 210 p. (Coleção No balanço das redes: tradição e tecnologia, v. 1)

GIL, A. C. Métodos e técnicas de pesquisa social. São Paulo: Atlas, 2009.

GOMES, H. F.; SANTOS, R. R. Atividades de mediação para leitura e escrita: uma análise dos níveis de mediação em experiências realizadas por bibliotecas de universidades públicas. Ciência da Informação, v. 43, n. 2, 2014.

GOMES, H. F. Protagonismo social e mediação da informação. Logeion: filosofia da informação, v. 5, n. 2, p. 10-21, 2019.

GULKA, J. A.; LUCAS, E. R. O. O bibliotecário enquanto personagem na contribuição para a ética em periódicos científicos. In: MATOS, J. C. (Orgs). Reflexões sobre ética na gestão da informação. Florianópolis, SC: UDESC, 2018. 
LÉVY, P. Cibercultura. São Paulo: Editora 34, 2010.

LÉVY, P. O que é virtual? São Paulo: Editora 34 Ltda, 2011.

SOARES, M. Alfabetização e letramento, caminhos e descaminhos. Pátio Revista Pedagógica, p. 96-100, fev. 2004.

SOARES, Magda. Novas práticas de leitura e escrita: letramento na cibercultura. Educ. Soc., Campinas, vol. 23, n. 81, p. 143-160, dez. 2002.

TFOUNI, L. V. Letramento e alfabetização. São Paulo: Cortez, 2010.

VARELA, A. V.; BARBOSA, M. L. A.; FARIAS, M. G. G. Humanismo e tecnologia na perspectiva da competência informacional e midiática. Revista Brasileira de Biblioteconomia e Documentação, v. 13, n. Especial, p. 280-300, 2017.

\title{
THE RELATIONSHIP OF READING AND INFORMATION COMPETENCE WITH THE LITERACY PROCESS IN THE DIGITAL AGE
}

\begin{abstract}
Introduction: Writing, information and communication technologies enhance the dissemination of information, enabling the recovery of printed, electronic and digital works in various types of media such as books, periodicals, videos and web sites. Through the use of technological resources huge volumes of information are made available, making it necessary for the contemporary subject to develop competences in the field of information and reading aimed at promoting meaningful learning as a result of the use of different text and hypertext modalities; permeating the interest, the need and the pleasure of reading. Objective: The presented scenario requires to analyze the development of reading competence and information competence related to the literacy process in the digital age. Methodology: Through a descriptive and exploratory research characterized at first as bibliographic, themes are identified and guidelines for competences developed in the library, school, cyberspace, at the university and other collaborative environments of (in)formation, education and culture. Results: During the analysis of the themes and directions that comprise the reading competence and information competence interrelated with the literacy process, it appears that the access of the modalities of multimodal readings and the comprehension capacity are essential for the appropriation of (hyper)text. It is identified that the exercise of critical reading, acquired through collaborative learning, requires processes of construction of practices and reading projects related to the ethical use of information, thus depending on a combination of knowledge and social attitudes in the digital age. Conclusions: During the development of the research it is noticed that the information and knowledge society requests from the reader subject competences that depend on the combination of skills (know how to do), knowledge (know how to be) and attitudes (know how to act) in the field of information and reading, as well as the acquisition of cognitive skills and attitudes related to writing in the context of alphabetization, along with the mobilization of reading practices socially constituted by the literacy process.
\end{abstract}

Descriptors: Information competence. Reading competence. Literacy in the digital age. Information and knowledge society. 


\title{
LA RELACIÓN DE LA COMPETENCIA LECTORA Y EN INFORMACIÓN COM EL PROCESO DE LETRAMIENTO
}

\begin{abstract}
RESUMEN
Introducción: Las tecnologías de escritura, información y comunicación mejoran la difusión de información, permitiendo la recuperación de trabajos impresos, electrónicos y digitales en varios tipos de medios, tales como libros, publicaciones periódicas, videos y sitios web. Mediante el uso de recursos tecnológicos, se ponen a disposición enormes volúmenes de información, lo que hace necesario que el sujeto contemporáneo desarrolle competencias en el campo de la información y la lectura diseñado para promover el aprendizaje significativo como resultado del uso de diferentes modalidades de texto e hipertexto impregnando el interés, la necesidad y el placer de leer. Objetivo: El escenario presentado requiere analizar el desarrollo de la competencia lectora y la competencia en información relacionada con el proceso del letramiento en la era digital. Metodología: A través de una investigación descriptiva y exploratoria caracterizada al principio como bibliografica, se identifican los temas y se identifican las pautas para las competencias desarrolladas en la biblioteca, la escuela, el ciberespacio, en la universidad y otros entornos colaborativos de (in)formación, educación y cultura. Resultados: Durante el análisis de los temas y las direcciones que comprenden las competencias lectora y en información interrelacionadas con el proceso del letramiento, se verifica que el acceso a las modalidades de lectura multimodal y la capacidad de comprensión son esenciales para la apropiación del (hiper)texto. Se identifica que el ejercicio de lectura crítica, adquirido a través del aprendizaje colaborativo, requiere procesos de construcción de prácticas de lectura y proyectos relacionados con el uso ético de la información, lo que depende de una combinación de conocimiento y actitudes sociales en la era digital. Conclusiones: Durante el desarrollo de la investigación, se observa que la sociedad de la información y del conocimiento solicita del lector competencias que dependen de la combinación de habilidades (saber hacer), conocimiento (saber cómo ser) y actitudes (saber cómo actuar) en el campo de la información y la lectura, así como la adquisición de habilidades cognitivas y actitudes relacionadas con la escritura en el contexto de la alfabetización, junto con la movilización de prácticas de lectura socialmente constituidas por el proceso del letramiento.
\end{abstract}

Descriptores: Competencia en información. Competencia lectora. Letramiento en la era digital. Sociedade de la información y el conocimiento.

Recebido em: 09.01.2020

Aceito em: 04.02.2021 